\title{
Contribuições arquivisticas à tomada de decisão nas instituições contemporâneas
}

\author{
Archival contributions to decision-making institutions in \\ contemporary
}

\author{
Paulo Kiyoshi Nishitani ${ }^{1}$; Nádina Aparecida Moreno²; Rosane Suely Alvares \\ Lunardelli ${ }^{3}$; Neila Célia Soares ${ }^{4}$
}

\begin{abstract}
Resumo
O processo decisório, a tomada de decisão nos mais variados segmentos institucionais depende, entre outros fatores, do acesso as informações relevantes e em tempo hábil. Manter as informações e os documentos organizados, recursos humanos capacitados, espaço físico e equipamentos adequados, tornam possíveis o eficiente e eficaz acesso à documentação. De acordo com esse cenário, é proposta desse estudo, evidenciar a necessidade e importância da implantação do processo de Gestão Documental nesses contextos. Considerado procedimento característico da práxis arquivística, a Gestão Documental engloba atividades relativas à produção documental, ressaltando critérios para sua elaboração; a utilização, na qual se dá o mapeamento do fluxo a ser percorrido pelos documentos e a ultima etapa, a destinação, fase em que os documentos são analisados, selecionados e indicados para a guarda permanente ou descarte.
\end{abstract}

Palavras-chave: Gestão documental. Tomada de decisão. Arquivologia. Gestão de documentos.

\begin{abstract}
The decision making process, decision making in various institutional segments depends, among other factors, access relevant information and timely. Keep the information and documents organized, trained human resources, physical space and appropriate equipment, makes possible the efficient and effective access to documentation. According to this scenario is proposed in this study highlight the need and importance of implementing the process of document management in these contexts. Considered typical procedure of praxis archival Document Management includes activities related to document production, emphasizing criteria for their development, the use, which gives the mapping of the flow to be covered by the documents and the last step, the destination, where the phase documents are reviewed, selected and designated for permanent custody or disposal.
\end{abstract}

Key-words: Document management. Decision-making. Archival science.

\footnotetext{
${ }^{1}$ Mestrando no programa de Mestrado Profissional em Gestão da Informação do Depto de Ciência da Informação -UEL. Email: paulo.nishitani@sercomtel.com.br

${ }^{2}$ Doutora em Ciência da Informação pela UFMG. Professor Departamento de Ciência da Informação da Universidade Estadual de Londrina., atualmente Reitora da Universidade Estadual de Londrina

${ }^{3}$ Doutora em Estudos da Linguagem pela Universidade Estadual de Londrina. Professor Adjunto e Vice Chefe do Departamento de Ciência da Informação da Universidade Estadual de Londrina. Email: lunardelli@uel.br.

${ }^{4}$ Mestranda no programa de Mestrado Profissional em Gestão da Informação do Depto de Ciência da Informação -UEL. Email: neila@uel.br
} 


\section{Introdução}

A realidade atual do mercado econômico, em especial a concorrência acirrada entre os mais diversos segmentos organizacionais, é fato, propiciou mudanças consideráveis no modus operandi de cada empresa ou instituição. Em decorrência, o processo decisório, ou seja, a tomada de decisão acertada e em tempo hábil, - em qualquer nível e pelos diversos atores responsáveis pelo processo -, revela-se de suma importância para a sobrevivência desses segmentos.

Na perspectiva de Lousada e Valentim (2011, p. 163), tomar decisões é "inerente ao trabalho de qualquer pessoa. No caso dos gestores, a tomada de decisão faz parte de sua função, ou seja, é tão importante quanto qualquer outra atividade sob sua responsabilidade".

Para Choo (2003, p. 42), a tomada de decisões na organização é racional não apenas em espírito (e aparência), mas na execução: a organização é intencionalmente racional, mesmo que seus membros tenham sua racionalidade limitada, e complementa ao afirmar que:

Metas e objetivos são estabelecidos de antemão, e quando os participantes encontram problemas na busca desses objetivos, procuram informações sobre as alternativas e consequências, e avaliam os resultados de acordo com os objetivos e preferências. $\mathrm{O}$ modelo tem uma característica linear de troca de energia, com foco no fluxo de informações nos processos decisórios da organização.

Uma decisão sempre precisa ser tomada diante de um problema que possui mais que uma alternativa para a sua solução. Mesmo quando, para solucionar um problema, existe uma única ação a ser executada, têm-se a alternativa de tomar ou não essa opção.

Shimizu (2006, p. 17), ao ressaltar a dificuldade em se tomar decisões, argumenta que o processo de tomada de decisão, é de modo geral, quase sempre caótico e complexo.

[...] caótico porque os indivíduos e as organizações não possuem visão clara e completa dos objetivos e dos meios que definem o problema de decisão.
Complexo porque a incerteza, a falta de estruturação e o tamanho do problema podem inviabilizar a aplicação sistemática da maior parte das metodologias de decisão, as quais frequentemente utilizam julgamentos subjetivos.

Os principais aspectos dos sistemas decisórios de uma organização, segundo Choo (2003), são demonstrados na figura abaixo

Figura 1 - Aspectos dos sistemas decisórios

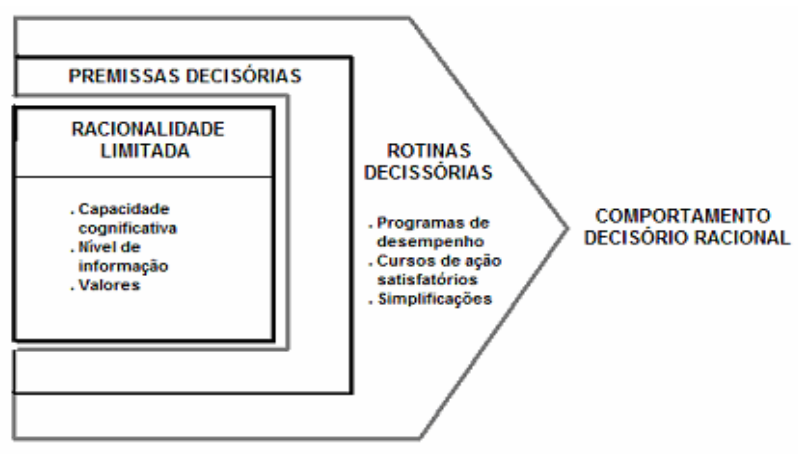

Fonte: Choo (2003, p. 44).

Bazerman (2004, p. 197) indica fragilidades na tomada de decisões ao argumentar que:

[...] embora quase todos nós tomemos decisões suficientemente boas para tocar a nossa via no diaa-dia, todos temos muita margem para melhorar nosso julgamento. Seres humanos não são "maus" tomadores de decisões, mas, na verdade, ficamos aquém do comportamento objetivamente racional e o fazemos de modos específicos e sistemáticos. A pergunta crítica é o que podemos fazer para corrigir essas deficiências. Pesquisadores da decisão têm respondido a essa pergunta com uma variedade de conselhos prescritivos que se somam ao seu trabalho descritivo.

Dando continuidade, o autor, na mesma obra e página, apresenta cinco itens ou estratégias que devem ser observadas para a melhoria do processo decisório: "adquirir experiência e conhecimento técnico; reduzir o viés do seu julgamento, adotar o ponto de vista do agente externo, usar modelos lineares e ajustar previsões intuitivas". 
Para Shimizu (2006, p. 19), o sucesso no processo de tomada de decisão depende de inúmeros fatores, tais como:

a) responsabilidade perante leis e penalidades; b) especialização - baseada em conhecimentos teóricos e práticos de especialistas; c) coordenação - para transmitir as ordens que devem ser cumpridas e coordenar o processo de decisão; d) cacife - para cobrir eventuais fracassos em algumas frentes; e) tempo - pois o tempo curto pode minimizar a incerteza, mas pode aumentar o risco de uma decisão apressada, enquanto o tempo longo pode trazer novas perspectivas de decisão, mas aumenta o nível de incerteza.

Harrison (1993) cita que o processo de tomada de decisão é um produto da cultura no qual a decisão acontece e, ao mesmo tempo, influencia essa cultura. Além disso, afirma que este processo, no atual mundo mutável e complexo, leva em conta aspectos relevantes de muitas disciplinas, não só da Economia, da Matemática e da Estatística.

Seguindo Jiambalvo (2002, p. 3), pode-se entender que

[...] a tomada de decisão é a parte integrante do processo de planejamento e controle - as decisões são tomadas para recompensar ou punir os gerentes, para alterar as operações ou revisar os planos. A empresa deve adicionar um novo produto? Deve abandonar um produto existente? Deve fabricar um componente usado na montagemdo seu principal produto ou contratar uma outra empresa para produzi-lo? Que preço a empresa deve cobrar por um novo produto? Essas perguntas indicam apenas algumas das decisõeschave que as empresas enfrentam. E a forma como tomam essas decisões irá determinar sua rentabilidade futura e, possivelmente, a sua sobrevivência [...].

Gomes (2006) ressalta que, na vida profissional, bem como na vida pessoal, os problemas implicam soluções de difícil decisão, o que se considera uma tomada de decisão complexa. De modo geral, esses problemas possuem pelo menos algumas das seguintes características: a) os critérios de resolução do problema são em número de, pelo menos, dois e conflitam entre si; b) tanto os critérios como as alternativas de solução não são claramente definidos e as conseqüências da escolha de dada alternativa com relação a pelo menos um critério não são claramente compreendidas; c) os critérios e as alternativas podem estar interligados, de tal forma que um critério parece refletir parcialmente outro critério, ao passo que a eficácia da escolha de uma alternativa depende de outra alternativa ter sido ou não também escolhida, no caso em que as alternativas não são mutuamente exclusivas; d) a solução do problema depende de um conjunto de pessoas, cada uma das quais tem seu próprio ponto de vista, muitas vezes conflitante com os demais; e) as restrições do problema não são bem definidas, e pode mesmo haver alguma dúvida a respeito do que é critério e do que é restrição; f) alguns dos critérios são quantificáveis, ao passo que outros só o são por meio de julgamentos de valor efetuados sobre uma escala; g) a escala para dado critério pode ser cardinal, verbal ou ordinal, dependendo dos dados disponíveis e da própria natureza dos critérios; h) várias outras complicações podem surgir num problema real de tomada de decisão, mas esses sete aspectos anteriores caracterizam a complexidade desse problema. Em geral, problemas dessa natureza são considerados mal estruturados.

O processo de tomada de decisões, segundo Laudon e Laudon (2004), nem sempre é realizado por um único indivíduo, mas por grupos ou organizações inteiras. Modelos organizacionais de tomada de decisões levam em conta as características burocráticas e políticas de uma organização. Algumas ações podem ser baseadas nos procedimentos operacionais, padrão da organização, porque afastar-se radicalmente das políticas vigentes envolve uma incerteza muito grande.

Moreno (2006) destaca que, quanto mais complexo e dinâmico for o ambiente, maior será o nível de incerteza ambiental. Assim, as organizações necessitam processar mais informações para apoiar o processo de tomada de decisão. Entretanto, essas informações precisam estarorganizadas, disponíveis, devem ser precisas para que, eficazmente, subsidiem a tomada de decisão. Porém, de acordo com a autora acima mencionada (MORENO, 2008, p. 86), “o que se detecta na atualidade é que as organizações, 
com ou sem fins lucrativos, apresentam, em sua grande maioria, burocracia excessiva em seus funcionamentos, fluxo de trabalho mal desenhado, produção de grande quantidade de documentos desnecessários, [...]." De acordo com esse contexto, para Moreno (2008, p. 86), "resulta, assim, que essa volumosa massa documental, sem uma gestão eficaz conduz a dificuldades de acesso à informação e também à ocupação de espaço físico, significando um dispêndio financeiro considerável".

Em um processo de tomada de decisão, tornase evidente a importância de se ter disponível informações relevantes e atualizadas. Padoveze (2000, p. 44) ressalta o valor da informação, ao relacioná-la: “a) a redução da incerteza no processo de tomada de decisão; b) a relação do benefício gerado pela informação versus custo de produzi-la; c) o aumento da qualidade da decisão".

Em que pese a valorização da informação pelos mais variados membros da organização ou instituição, observa-se que, de modo geral, esses dados / informações / conhecimentos estão espalhados pela empresa ou estão sob a custódia de poucos profissionais. Ao reportar-se à importância desses fatores no processo decisório, Angeloni (2003, p. 19) ressalta que "esses [documentos/ informações] normalmente estão dispersos, fragmentados e armazenados na cabeça dos indivíduos [...]."

Ora, de nada adianta a organização possuir essas informações se elas não estão devidamente armazenadas. Nesse sentido, vale lembrar que a falta de organização dos documentos dificulta ou impossibilita o seu acesso e apropriação.

De acordo com o panorama sucintamente delineado, evidencia-se então a necessidade de se estabelecer e seguir procedimentos rotineiros no que tange a produção, conservação e disponibilização de informações/documentos (termos aqui empregados como sinônimos). No âmbito da Arquivologia, esses procedimentos fazem parte do processo de Gestão Documental.

\section{A Gestão de Documentos ou Gestão Documental}

A Arquivologia, também conhecida como Arquivística, é a área do conhecimento "que tem por objeto o conhecimento da natureza dos arquivos e das teorias, métodos e técnicas a serem observados na sua constituição, organização, desenvolvimento e utilização." (DICIONÁRIO..., 1996, p. 5).

Diante do afirmado, torna-se evidente que gerenciar documentos, sob as premissas canonizadas pela Arquivologia, "garante às empresas públicas ou privadas obter maior controle sobre as informações que produzem e/ou recebem, racionalizar os espaços de guarda de documentos, desenvolver com mais eficiência e rapidez suas atividades, atender adequadamente clientes e cidadãos" (RONCAGLIO; SZVARÇA; BOJANOSKI, 2004, p. 5).

As ações anteriormente mencionadas consistem no controle das informações produzidas e/ou recebidas e racionalização do espaço físico ou do espaço virtual, uma vez que em uma organização coexistem documentos impressos e em formato eletrônico. Essas ações fazem parte do processo arquivístico denominado Gestão de Documentos ou Gestão Documental.

$\mathrm{Na}$ perspectiva de Moreno (2008, p. 82) “A gestão é entendida como a ação ou efeito de administrar, ou seja, é toda a atividade dirigida com o objetivo de obter e administrar os recursos necessários para o cumprimento dos objetivos, de qualquer organização.” Em decorrência, entende-se que a gestão de documentos é o trabalho de assegurar que a informação seja administrada com economia e eficácia; que seja recuperada, de forma ágil e eficaz, para subsidiar as ações das organizações e tornar mais seguro o processo de tomada de decisão. Nesse sentido, a gestão documental ou gestão de documentos surge como uma ferramenta indispensável à otimização do uso das informações contidas nos mais variados suportes e nos mais diversos espaços institucionais. 
Segundo Burnet (apud JARDIM, 1987, p. 35),

[...] a gestão de documentos é uma operação arquivística entendida como o processo de reduzir seletivamente a proporções manipuláveis a massa de documentos, que é característica da administração moderna, de forma a conservar permanentemente os que têm um valor cultural futuro sem menosprezar a integridade substantiva da massa documental para efeitos de pesquisa

Reportando-se ao cenário que propiciou a sistematização das atividades de Gestão de Documentos, Paes (2002), apresenta que o reconhecimento da importância dos documentos só foi mais acentuado e difundido após a Segunda Guerra Mundial. A partir dessa data, com o avanço da ciência e tecnologia, a produção de documentos cresceu em níveis elevados que superaram em muito a capacidade de controle e organização das empresas, que se viram forçadas a desenvolver trabalhos e buscar soluções para a gestão destes acervos acumulados.

A Lei Federal no 8.159, de 08/01/1991, em seu Art. $3^{\circ}$, considera a gestão de documentos "como o conjunto de procedimentos e operações técnicas referentes à sua produção, tramitação, uso, avaliação e arquivamento em fase corrente e intermediária, visando a sua eliminação ou recolhimento para a guarda permanente" (BRASIL, 1991).

Gestão de documentos, segundo a NBR 9578 da ABNT (ASSOCIAÇÃO BRASILEIRA DE NORMAS TÉCNICAS, 1986, p. 1), é uma “[...] metodologia de programas para controlar a criação, o uso, a normalização, a manutenção, a guarda, a prática e a destinação de documentos".

Com o intuito de tornar mais clara as questões aqui apresentadas, seguem-se algumas explicações quanto ao significado de documento e documento de arquivo.

Para Briet (1970, p. 1), documento é todo índice concreto ou simbólico, conservado ou registrado, com a finalidade de representar, de reconstituir ou de provar um fenômeno físico ou intelectual. O autor ainda questiona:
[...] uma estrela é um documento? Um seixo levado pela torrente é um documento? Um animal vivo é um documento? Não. Mas são documentos as fotografias e os catálogos das estrelas, as pedras de um museu de mineralogia, os animais catalogados e expostos num Zoo.

A conceituação clássica e genérica de documento, de acordo, com Bellotto (2007, p. 35), é que "documento é qualquer elemento gráfico, iconográfico, plástico ou fônico pelo qual o homem se expressa". Segundo a autora, pode ser um livro, uma tela, uma escultura, um dossiê, "enfim, tudo o que seja produzido por razões funcionais, jurídicas, científicas, técnicas, culturais ou artísticas, pela atividade humana" (BELLOTTO, 2007, p. 35).

De acordo com essa premissa, torna-se evidente a expressiva gama de artefatos ou de fontes informacionais que compõem a classe de documentos.

Sprague Júnior (apud SILVA, 2001, p. 16) considera que os documentos podem ser fontes de rendimentos em negócios de duas formas: $\mathrm{Na}$ primeira, eles são objetos do negócio, são a fonte direta de rendimentos para uma empresa e/ ou organização. Na segunda, darão suporte com informações necessárias para gerenciar, controlar e operar uma empresa e/ou organização.

Para o autor, os valores dos documentos para dar suporte ao desempenho organizacional podem ser agrupados em três categorias: documento como possibilidade de comunicação organizacional, como mecanismo para processos básicos de negócios e elemento fundador da memória organizacional.

Em contrapartida, os documentos de arquivos, ainda que também se constituam em grande numero de fontes, revestem-se de particularidades, no que tange ao numero de exemplares, o motivo pelo qual foi criado, a relação que estabelece com o órgão que o produziu, como é explicitado na literatura da Área.

De acordo com Bernardes (1998, p. 44), o documento de arquivo “[...] é todo registro de informação original, único e autêntico, que resulta da acumulação em processo natural por uma entidade 
produtora no exercício de suas competências, funções e atividades, independentemente de seu suporte [...]."

Com relação à sua gênese, é possível afirmar que são elaborados com propósitos preestabelecidos, no âmbito das relações entre instituições ou pessoas.

Em decorrência desses aspectos, Bellotto (2007, p. 37), ao ressaltar o caráter orgânico desses documentos, uma vez que existe uma relação natural entre documentos de um arquivo, em decorrência das atividades das entidades, - públicas ou particulares que o acumulou, apresenta que eles "Surgem, pois, por motivos funcionais administrativos e legais. Tratam, sobretudo, de provar, de testemunhar alguma coisa." De acordo com esse enfoque, importa lembrar que os documentos arquivisticos existem em qualquer suporte, inclusive aqueles nascidos ou migrados para o formato eletrônico.

Para Billotta et al. (1984, p. 74), "os documentos arquivísticos, porque nascem do próprio agir da organização, espelham fielmente sua evolução, tempo e relação com o meio ambiente."

Acompanhando a linha de raciocínio, Negreiros (2007, p. 164) elucida que:

[...] os documentos arquivísticos, numa concepção contemporânea, estão em qualquer suporte, inclusive os legíveis por máquina; possuem os elementos constitutivos: conteúdo, forma ou estrutura, ação, pessoas, relação orgânica e contexto; e mantêm suas características (autenticidade, naturalidade, interrelacionamento e unicidade) intactas.

No que diz respeito aos objetivos da Gestão de Documentos, torna-se claro que o processo possibilita, entre outros aspectos, a melhor organização dos documentos, evita a criação e a conservação de documentos considerados sem importância para a instituição; propicia a distinção entre documentos de uso corrente, eventual e aqueles que, apesar de não serem consultados com regularidade, devem ser de guarda permanente.

De acordo com o panorama apresentado, é possível então concluir que a Gestão de Documentos: a) oferece maior proteção à informação, uma vez que evita a dispersão dos documentos e o seu acesso por pessoas não autorizadas e privilegia sua conservação ou integridade física e intelectual; b) propicia a redução criteriosa da massa documental e do espaço físico ou eletrônico (imaterial) utilizado, fato esse que concorre para a racionalização e até diminuição dos custos; c) contribui de forma rápida e eficiente, para o acesso e uso dos documentos existentes.

É consensual na literatura especializada que o processo de Gestão de Documentos é composto por três etapas: produção, utilização e destinação final. Na primeira etapa, elabora padrões de produção dos documentos, desde seu suporte até a organização/ apresentação do seu conteúdo.

$\mathrm{Na}$ segunda, a etapa da utilização indica os procedimentos a serem seguidos no que tange ao recebimento dos documentos, sua classificação, distribuição, empréstimo e/ou consultas. Em outras palavras, aponta o caminho ou o fluxo que os documentos percorrerão.

A destinação final, considerada último estágio do processo de gestão, diz respeito à estipulação dos prazos de guarda dos documentos.

O Ciclo Vital dos Documentos constitui um dos fundamentos que sustentam a práxis arquivística. Nele se determina as "fases por que passam os documentos, desde o momento em que são criados até sua destinação final" (DICIONÁRIO..., 1996, p. 15), e cria-se a Tabela de Temporalidade, instrumento elaborado pelos responsáveis dos Arquivos, com a finalidade de indicar os prazos de guarda dos documentos. De acordo com esse princípio, os documentos poderão ser eliminados, transferidos, enviados ao arquivo permanente e/ ou migrado para outro suporte, por meio de sua digitalização e microfilmagem.

O Ciclo Vital dos Documentos, a Teoria das Três Idades, segundo Rousseau e Couture (1998, p. 112), "se baseia em dois valores que os arquivos têm ou podem ter, ou seja, o valor administrativo e o valor de testemunho". Para eles, "o que poderia 
ser o conceito das duas idades tornou-se o das três idades, graças ao crescimento incontrolável que caracterizou, a partir dos anos de 1940, a criação dos documentos" produzidos pelas administrações. Foi essa explosão documental que evidenciou a necessidade de um período intermediário entre $\mathrm{o}$ ativo e o inativo.

De acordo com a literatura, e especificamente o Arquivo Nacional (2004,p. 21), as três fases ou idades pela quais passam dos documentos possibilitam a criação dos arquivos: "[...] Corrente: conjunto de documentos, em tramitação ou não, que, pelo seu valor primário, é objeto de consultas freqüentes pela entidade que o produziu, a quem compete a sua administração". O Arquivo Intermediário, o qual, de acordo com o texto, constitui-se em "conjunto de documentos originários de arquivos correntes, com uso pouco freqüente, que aguarda destinação." (ARQUIVO NACIONAL, 2004, p. 24). Por ultimo (mas não menos importante), o Arquivo Permanente, também chamado de arquivo histórico, constitui o "conjunto de documentos preservados em caráter definitivo em função de seu valor [...]. (ARQUIVO NACIONAL, 2004, p. 26).

\section{Considerações Finais}

No mundo contemporâneo, a informação adequada, acessada em tempo hábil, adquire valor inestimável para qualquer segmento da sociedade. No que diz respeito ao papel da informação nas organizações, Lousada e Valentim (2011, p. 148) argumentam que:

[... a organização que não tem informação para subsidiar suas decisões estratégicas, bem como a sua gestão, estará em desvantagem em relação às outras organizações do mesmo segmento, porquanto não será possível analisar, em tempo mínimo, as alternativas de decisão, além de reproduzir eficazmente o resultado decorrente da decisão tomada

O processo decisório nos mais variados segmentos institucionais, como já mencionado, depende, entre outros fatores, do acesso as informações relevantes e em tempo hábil. Em decorrência, torna-se evidente a intima relação entre a tomada de decisão e a organização dos arquivos, uma vez que a dispersão documental decorrente da falta de organização e tratamento dos documentos dificultará ou impossibilitará a identificação de estratégias ou caminhos a serem seguidos nesse processo. A organização do arquivo de uma instituição, com ou sem fins lucrativos, pressupõe, entre outros aspectos, uma gestão documental de qualidade.

Caracterizada como relevante procedimento arquivístico, a Gestão Documental abarca aspectos relativos à produção, os aspectos intrínsecos e extrínsecos do documento e a sua utilização. Nessa etapa ocorre o delineamento do fluxo. a ser percorrido pelos documentos. A última etapa é a destinação, fase em que os documentos são analisados, selecionados e indicados para a guarda permanente ou descarte, independentemente do suporte no qual está registrado.

Dentro desse contexto, torna-se evidente a importância e necessidade a presença do Arquivista à frente da gestão de documentos, uma vez que possui competências específicas para nesse processo. O conhecimento técnico e científico requerido, que capacita o arquivista a atuar em todas as fases do processamento documental, - independentemente dos suportes nos quais se encontram registrados os documentos. Por isso, esse profissional caracterizase como autêntico mediador entre os documentos, as informações e os vários membros da instituição ao qual se vincula.

Ao discorrer acerca das características do profissional em um cenário atual, Bellotto (2007, p. 301) aponta com relevantes as "[...] qualidades de adaptabilidade, capacidade de compreensão e escuta relativamente ao produtor, ao pesquisador, ao cidadão".

De acordo com esse cenário, foi proposta desse estudo, apresentar a Gestão de Documentos como processo de grande valia à tomada de decisão 
em qualquer nível organizacional, uma vez que possibilita, entre outros fatores, a recuperação, em tempo hábil, da informação necessitada, bem como o relevante papel que o Arquivista assume nesse contexto.

\section{Referências}

ARQUIVO NACIONAL. Subsidios para um dicionário brasileiro de terminologia arquivística. Rio de Janeiro, 2004. Disponível em: <http://www. arquivonacional.gov.br/download/dic_term_arq. pdf $>$. Acesso em: 12 de maio de 2012.

ASSOCIAÇÃO BRASILEIRA DE NORMAS TÉCNICAS. NBR 9578: arquivos: terminologia. Rio de Janeiro: ABNT, 1986.

ANGELONI, M. T. Elementos intervenientes na tomada de decisão. Ciência da Informação, Brasília, v. 32, n. 1, abr. 2003. Disponível em: <http://www. scielo.br/pdf/ci/v32n1/15969.pdf $>$. Acesso em: 10 abr. 2012 .

BAZERMAN, M. H. Processo decisório: para cursos de administração e economia. Rio de janeiro: Elsevier, 2004.

BELLOTTO, H. L. Arquivos permanentes: tratamento documental. Rio de Janeiro: Editora FGV, 2007.

BERNARDES, I. P. Como avaliar documentos de arquivo. São Paulo: Arquivo do Estado, 1998. (Projeto como fazer, 1).

BRASIL. Lei $n^{\circ}$ 8.159, de 8 de janeiro de 1991. Dispõe sobre a política de arquivos públicos e privados e dá outras providências. Disponível em: $<$ http://www.planalto.gov.br/ccivil_03/leis/L8159. htm>. Acesso em: 10 abr. 2012.

BILLOTTA, Sérgio et al. As experiências da FUNDAP na área das comunicações administrativas e arquivos. Cadernos FUNDAP, São Paulo, v. 4, n. 8, p. 74-97, 1984.

BRIET, S. O que é documentação. Tradução de Maria Nazareth Fendt. Niterói: Universidade Federal Fluminense, 1970.
CHOO, C. W. A organização do conhecimento: como as organizações usam a informação para criar significado, construir conhecimento e tomar decisões. São Paulo: Editora SENAC, 2003.

DICIONÁRIO DE TERMINOLOGIA ARQUIVÍSTICA. São Paulo: AAB-SP, 1996.

GOMES, L. F. A. M. Tomada de decisão gerencial: enfoque multicritério. São Paulo: Atlas, 2006.

HARRISON, E. F. Inter-disciplinary models of decision making. Management Decision, York, v. 31, n. 8, p. 27-33, 1993.

JARDIM, J. M. O conceito e a prática de gestão de documentos. Acervo, Rio de Janeiro, v. 2, n. 2, p. 35-42, jul./dez. 1987.

JIAMBALVO, J. Contabilidade gerencial. Rio de Janeiro: LTC, 2002.

LAUDON, K. C.; LAUDON, J. P. Sistemas de informações gerenciais: administrando a empresa digital. São Paulo: Prentice Hall, 2004.

LOUSADA, M.; VALENTIM, M. L. P. Modelos de tomada de decisão e sua relação com a informação orgânica. Perspectivas em Ciência da Informação, Belo Horizonte, v. 16, n. 1, p. 147-164, jan./mar. 2011.

MORENO, N. A. A informação arquivística no processo de tomada de decisão em organizações universitárias. 2006. Tese (Doutorado em Ciência da Informação) - Escola de Ciência da Informação da Universidade Federal de Minas Gerais, Belo Horizonte, 2006.

- Gestão documental ou gestão de documentos: trajetória histórica. In: BARTALO, Linete; MORENO, Nádina Aparecida (Org.). Gestão em arquivologia: abordagens múltiplas. Londrina: EDUEL, 2008, p. 71-88.

NEGREIROS, L. R. Sistemas eletrônicos de gerenciamento de documentos arquivísticos: um questionário para escolha, aplicação e avaliação. 2007. 246 f. Dissertação (Mestrado em Ciência da Informação) - Escola de Ciência da Informação, Belo Horizonte, 2007. Disponível em: <www. egov.mg.gov.br/files/conteudos/mestradoleandro ribeiro_negreiros.pdf $>$ Acesso em: 25 jun. 2008. 
PADOVEZE, C. L. Sistemas de informações contábeis: fundamentos e análise. 2. ed. São Paulo: Atlas, 2000.

PAES, M. L. Arquivo: teoria e prática. Rio de Janeiro: FGV, 2002.

RONCAGLIO, C.; SZVARÇA,D.R.;BOJANOSKI, S. de F. Arquivos, gestão de documentos e informação. Encontros BIBLI: Revista Eletrônica de Biblioteconomia e Ciência da Informação, Florianópolis, n. esp., 2. sem. 2004.

ROSSEAU, J. Y.; COUTURE, C. Os fundamentos da disciplina arquivística. Lisboa: Publicações Dom Quixote, 1998. 356 p.

SHIMIZU, T. Decisão nas organizações. São Paulo: Atlas, 2006.

SILVA, F. L. D. Gerenciamento eletrônico de documentos (GED):natureza,princípios eaplicações. 2001. Trabalho de Conclusão de Curso (Graduação em Ciência da Computação) - Universidade Federal de Mato Grosso, Cuiabá. 2001. Disponível em: $\quad<$ http:www.ufmt.br/cacomp/downloads/ monorafias/GED_NaturezaPrincipioAplicacao. pdf $>$. Acesso em: $\overline{10}$ nov. 2008. 
